\title{
At the crossroads: new paradigms of food security, public health nutrition and school food
}

\author{
Leah M Ashe* and Roberta Sonnino \\ School of Planning and Geography, Cardiff University, Glamorgan Building, King Edward VII Avenue, \\ Cardiff CF10 3WA, UK
}

Submitted 12 March 2012: Final revision received 9 August 2012: Accepted 13 August 2012: First published online 90 0ctober 2012

\begin{abstract}
Public health nutrition sits at the nexus of a global crisis in food, environmental and health systems that has generated - along with numerous other problems an urgent and changing problem of food insecurity. The 'new' food insecurity, however, is different from the old: it is bimodal, encompassing issues of both under- and over-consumption, hunger and obesity, quantity and quality; it has assumed a decidedly urban dimension; and it implicates rich and poor countries alike. The complexity of the expressions of this challenge requires new approaches to public health nutrition and food policy that privilege systemic, structural and environmental factors over individual and mechanistic ones. In this context, the current paper argues that school food systems rise with buoyant potential as promising intervention sites: they are poised to address both modes of the food security crisis; integrate systemic, structural and environmental with behavioural approaches; and comprise far-reaching, system-wide efforts that influence the wider functioning of the food system. Based on a discussion of Bogotá and other pioneering policies that explicitly aim to create a broader food system with longterm foundations for good public health and food security, the paper suggests a new research and action agenda that gives special attention to school food in urban contexts.
\end{abstract}

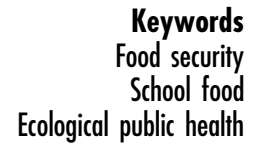

Food security School food Ecological public health
Public health nutrition sits at the nexus of a global crisis that involves and implicates an assembly of policy makers and researchers with widely diverse geographic, sectoral and disciplinary provenance. This, of course, is the coincident dysfunction in food, environmental and health systems that menaces human and planetary well-being with interrelated phenomena of global environmental change, environmental unsustainability and a new (bimodal) model of food insecurity ${ }^{(1-6)}$. Under a new and still unfolding scenario that has been variously labelled as the 'new food equation'(3), the 'world food equation, rewritten', (1) and the 'new fundamentals', good nutritional health is inaccessible to an enormous number of people but in different ways. Simply put, people suffer on the one hand from hunger and undernutrition and, on the other, from obesity and diet-related disease - and, in ironic injustice, the two problems sometimes simultaneously afflict individual households and even persons ${ }^{(7)}$. In other words, the current nutritional health crisis is increasingly manifesting bimodally to include widespread problems of both under- and mal-consumption (with over-consumption here considered as part of the latter). Adding to this complexity, there is also a new geography of food insecurity, which has become a problem in both rich and poor countries, and all the more so in the urban contexts that increasingly define the contemporary population dynamic ${ }^{(3,8-10)}$.

So far, public health nutrition scholarship has focused on two main aspects of the new world food order: the nutrition transition and the double burden, which threaten rich and poor countries alike with poor prospects for nutritional health and well-being ${ }^{(9-12)}$. Much less attention has been devoted to the complex and interrelated dimensions of the food system that effectively build (or fail to build) the opportunities for public bealth. As the editors of this journal acknowledge, 'dietary recommendations by themselves do not address social and economic inequities, ${ }^{(13)}$ - that is, the type of systemic and structural issues that hamper the achievement of better public health outcomes.

In the current paper, we focus on the emerging dynamics of the new food insecurity crisis and on its implications for public health nutritionists, who, we argue, can make a significant contribution to the definition of a food system that enables, promotes and enhances broader well-being. Theoretically, this requires the adoption of a systemic approach that embraces the fullness of the food system's identity: as the editors of this journal have recognized, 'we are as much a part of the public health community as we are of the nutrition 
community, with all that implies, ${ }^{,(13)}$. Practically, much can be learned from an analysis of the nature and promise of intervention contexts that might structurally and systemically address the complex issues of the new food insecurity. In the last part of the paper, we focus on one such context: school food systems. As we argue, school meals can serve an immediately remedial role in combating both under- and mal-consumption, while at the same time holding the potential to catalyse the broader political and systemic changes needed to redress food insecurity beyond the intermediate term. In the final part of the paper, we outline a new research and policy agenda that extols the potential of school food as a reform mechanism in cities, where some of the most innovative initiatives to combat food insecurity are beginning to emerge.

\section{Redefining public health nutrition in the new food (in-)security era}

Food security, like the public health nutrition field that must address it, is assuming a new dynamic. Far from being confined to rural areas of poor countries, food insecurity is now part of a more complex geography that embraces both the global North and the global South and that has three specific demographic and nutritional characteristics. First, like the global population itself, food insecurity is increasingly urban - a phenomenon that must be understood not as (only) a problem of underproduction by rural subsistence farmers but (also) as one of urban food access and use $\mathrm{e}^{(3,7,13-16)} *$ Second, food insecurity is increasingly an issue of both quality (malconsumption including over-consumption) and quantity (under-consumption). Yngve et $a l^{(13)}$ are among few to articulate this shift precisely as such, but others have also emphasized that the same explosion of obesity and nutrition-related disease be considered alongside hunger under a more expansive rubric of food security. Lang ${ }^{(5)}$, for example, suggests that the definition of food insecurity broaden sufficiently to 'factor(s) in all diet-related ill-health, not just hunger'. Third, the globally inclusive nature of the food security challenge has thus far been inadequately addressed. The practical consequences of this intellectual failure are important to recognize, since in many ways the issue has been better addressed in the global South, where the analysis of food insecurity ... has attached great importance to the cultural and social roles of food, emphasising autonomy, self-determination, cultural appropriateness, and other terms redolent of the social exclusion debate', themes the North has failed to appreciate to the same extent ${ }^{(17)}$.

\footnotetext{
* Indeed, this points to two major shortcomings of the thus far dominant approaches to understanding food insecurity, which have prioritized production-related problems in the food system at the expense of consumption-related ones and privileged attention to rural food security manifestations at the expense of urban ones ${ }^{(16)}$.
}

These shortcomings suggest that food security policy like public health nutrition - ought to shift towards an approach that is more intentionally systemic in nature and can respond at a structural level to the changing character of the global food system. If food insecurity is not simply a problem of insufficient production - which might, given sufficient resources, be easily enough resolved - but rather relates to a complex interaction of factors that encompass the entire ecology within which 'food security' happens, then addressing food insecurity implies addressing those factors. In other words, if an ecological model for approaching public health generally has merit - particularly in the current context - then so too does an ecological model for approaching food security specifically.

Thus far, however, the public health nutrition community has largely neglected the structural determinants of food security, and there are calls for it to shift attention towards policy-driven forms of intervention. As Caraher and Coveney ${ }^{(9)}$ state, focus should migrate 'from "post-swallowing" food and nutrition interventions to "pre-swallowing" conditions' and aim 'to make the social infrastructure conducive to healthy decisions about food'. Similarly, Lang ${ }^{(5)}$ calls for improved ways to conceive of and approach food security that 'focus on entire food chains'.

Many current approaches to food security refer to the prominent FAO definition (which establishes food security 'at the individual, household, national, regional and global levels' as a situation 'when all people, at all times, have physical and economic access to sufficient, safe and nutritious food to meet their dietary needs and food preferences for an active and healthy life ${ }^{\text {(18) }}$, often distilled into the four dimensions of food availability, access, utilization and stability ${ }^{(6,19-25)}$. These analytical dimensions prioritize key structural issues of spatial, economic and cultural access that become extremely relevant in the new multimodal food security context. Attending to the structural issues surrounding food access particularly in urban contexts where consumers are largely separate from the productive landscape and must depend on the market for food ${ }^{(13,26)}$ - leads to thorny but important theoretical questions that have largely been ignored by public health nutritionists. Indeed, predominant - even 'hegemonic'(27) - approaches to public health nutrition have emphasized mechanistic, biomedical and individualist understandings of health (which have correlated with intervention strategies based upon behaviour modification and assignation of individual responsibility) at the expense of more robust frameworks that better integrate social and structural factors $^{(9,27,28)}$.

Recent efforts to demand better attention to the systemic, structural and social factors that underlie nutrition and health outcomes are interrogating systems and relationships that are multifaceted, multifactorial and complex ${ }^{(29)}$. As Rayner ${ }^{(27)}$ explains, central to this approach is the idea that the only intellectual approaches and policy strategies sufficiently capable of dealing with the complexity of the 
food system are ecological ones that can address the many and multi-layered interactions between individual and environment - or, as Lang $^{(28)}$ states, approaches that acknowledge a 'right to be well'.

Although the concept of environmental public health (EPH) has not yet reached dominance, 'the recognition that people and the environment are the nodal points for public health are there', and some health institutions, including the US Institute of Medicine and the WHO's Commission on the Social Determinants on Health, express a de facto appreciation of $\mathrm{it}^{(27)}$. Indeed, as it has been pointed out, life science-based approaches to nutrition and health may well have their place, but 'societies are not surgeries, ${ }^{(28)}$, and the 'the likely solutions for nutrition problems lie less in unlocking biological pathways than in creating social environments that can deliver "correct" balance, (28). Public health nutrition, then, must turn to the question of building and bettering such environments. School food systems, as we argue below, emerge here as a promising intervention site, given their significant links with the health of humans and the environment - the main dimensions affected by the current food security crisis.

\section{School food at the crossroads}

School food has increasingly been seen as an important tool to redress the new dynamics implicating food systems, nutrition and health. Already in 2003, Bennett summarized how school feeding policies in developing countries have been used to pursue a central goal of improving the nutritional status of schoolchildren, while also addressing important issues of attendance, enrolment, cognitive development and gender imbalances, and more recent work has elaborated further evidence for the same themes.* In particular, by linking agricultural development with school feeding, improving access to education and building populations' capacity for participatory citizenship, innovative school food programmes in developing countries are seen to enhance food security and, en route, deliver other benefits such as enhanced livelihood opportunities, better natural resource management, higher incomes, smaller families and improved household management ${ }^{(30-34)}$.

Although the empirical evidence on the developmental impacts of school feeding initiatives is quite sketchy and fragmented, together the literature identifies a wide range of benefits associated with school food reforms that can all situate within a capacious understanding of the new food security paradigm. In general, the integrality and breadth of these reforms are such that they address food security both immediately (i.e. by providing caloric sustenance to

* See Bundy et al. ${ }^{(30)}$ for the most comprehensive and rigorous review of the benefits, challenges and evidence base for school feeding around the world. undernourished children and making fresh foods available to young people living in urban food deserts) and in the longer term (i.e. by embracing young citizens' structural role in the food chain and their socio-environmental potential in promoting healthier food habits).

In low-income countries, school food interventions have been used as part of the social safety net, to combat hunger and micronutrient-related undernourishment, and to improve educational access and attainment - goals that have been pursued with some documented success in countries as diverse as Bangladesh, Cote d'Ivoire, Burundi $^{(31)}$, Mali, Jamaica, Pakistan and Cambodia ${ }^{(30)}$, among others. Low- and middle-income countries have also used school food to address the other half of the double burden, and many, including Brazil, China, South Korea, Malaysia, Mexico, South Africa and Thailand, have created specific school-based strategies to tackle the onset of obesity and nutrition-related disease, largely through whole-school approaches designed to build a healthier food consumption culture ${ }^{(35)}$. Rich countries, too, have turned to school food to address the dynamics of the new food insecurity, and studies have examined its efficacy in relation to outcomes such as decreasing trends of overweight ${ }^{(36,37)}$ and increasing consumption of fruits and vegetables $^{(38,39)}$.

In this context, some multi-sectoral and multi-stakeholder efforts (such as Home-Grown School Feeding) have aimed to expand the transformative potential of school food reform through a focus on its capacity to boost local agricultural production and thus stimulate development beyond school walls ${ }^{(30,32)}$. Data show that school food can make an important contribution to the creation and stimulation of local economies. In East Ayrshire (Scotland), for example, school food reform has produced a Social Return on Investment Index (SROI) of above $6^{(40)}$, meaning that, for every $£ 1$ invested in the initiative, over $£ 6$ of value is created in economic, social, environmental and other outcomes $^{(41)} \dagger$ Similarly, in Albania, the purchase of locally produced foods for the school feeding project has generated paid employment in food processing and additional income for local farmers and bakers ${ }^{(31)}$.

Overall, there is a growing body of literature that emphasizes how school food reform is - or can be distinct from other efforts in several important ways. First, it is food chain systemic (rather than segmental), and this endows it with power to provoke structural changes throughout the entirety of the food system, all of which can be designed to improve food security. Second, it is state-led, rather than privately led, and this gives it

$\dagger$ Effectively, the SROI estimates the economic value of outcomes which often fail to be appreciated for their economic benefit. In this instance, Footprint Consulting used indicators spanning environmental, economic, health and 'other' categories, including, for example, the value of new land brought into organic production; the reduction in future environmental costs associated with lower carbon emissions; the reduction in future health costs; and the costs needed to otherwise achieve similar reputational advantage ${ }^{(41)}$. 
heightened reach, legitimacy and implementation capacity $^{(42,43)}$. Third, because it targets poor children, it is positioned specifically to reach populations particularly at risk of food insecurity in both its forms of hunger and obesity $^{(30,44-46)}$.

In the next section, we explore this multidimensional potential of school food reform through a focus on some of the most innovative initiatives that have recently been implemented around the world. Our analysis shows that this multidimensional potential tends to express itself at its best when it is informed by a broader rights-based approach to food and health. While, in some cases, such an approach is embedded in national food cultures, in others it is emerging at the local (especially municipal) level, with cities like Bogotá taking the lead in devising school food policies that explicitly link food security with health nutrition. As we discuss in the Conclusions, for researchers and practitioners alike, this raises important questions about the pioneering role of cities in devising and implementing a renewed ecological ethics for good health and better food security.

\section{The right to food security: Bogotá and the promise of school food}

The available literature on school food systems points to the importance of the underlying vision and cultural values in shaping the developmental outcomes of reform initiatives (including ones related to nutrition). In synthesis, the most successful reforms tend to occur within a wider political and legislative context that views school food as a health and well-being, rather than a commercial, service ${ }^{(42)}$. In Japan, for example, school meals have been actively designed around the idea of using local production and local consumption as a means to stimulate children's familiarity with the local culture and food system $^{(47)}$. Likewise, Italy has traditionally promoted its school food service as an integral part of children's right to education (of which local food culture is an important component) and, more generally, of consumers' right to health ${ }^{(48)}$. Brazil has also recently revolutionized its school food system by embedding it into a food security and sovereignty framework that stipulates a right to food security and obliges municipalities to procure local produce directly from family farmers $^{(47)}$. In addition to facilitating the implementation of initiatives that empower local farmers to be able to supply fresh produce, this type of approach tends to enhance civic participation in school food reform, as citizens acquire the right and the responsibility to monitor food safety and quality (as happens in both Italy and Brazil).

In the context of these national political cultures, public food reform tends to occur because of State action and support. This has been the case, for example, in Rome ${ }^{(48)}$ and Belo Horizonte ${ }^{(49)}$. In other countries, however, reforms are occurring despite the lack of a supportive national context - a trend that brings to the fore the role and potential of municipal governments as food system innovators in the new food security era. One of the most illustrative and pioneering examples in this sense is that of Bogotá, one of the first cities that has situated schools meals with intention and specificity as part of a food security project that is based on notions of rights, justice and equity.

Bogotá is the second-to-most inequitable city in South America; its current Gini coefficient* of 0.61 reflects not only gross actual income inequality but also recent growth in inequality, which increased by $24 \%$ between 1991 and 2005. On the other hand, however, the city has benefited from politically progressive actions by recent administrations, and it is recognized for relatively high levels of participation and accountability ${ }^{(50)}$. In 2004, Mayor Lucho Garzón introduced the anti-poverty and anti-hunger campaign 'Bogotá sin hambre' ('Bogotá without hunger'), continued in 2007 under the 'Bogotá bien alimentada' ('Bogotá well-nourished) label. Both policies rest upon a foundational assertion that all people have a right to food security and that the state has the responsibility for ensuring that those rights are met ${ }^{(51-53)}$. The initiatives have integrated local policy with national support (e.g. funding), and the city has been as an exemplar of insulating progressive reforms from the caprice of political ebb and flow ${ }^{(50)}$.

A fundamental part of both of these food security policies has been the school food programme, which the administration views multifunctionally as a means to address immediate situations of short-term hunger, to combat problems of long-term malnutrition and poor health, and to improve educational enrolment, attendance, retention and attainment. Municipal efforts in Bogotá have included creating new school food programmes in schools that did not previously offer them; introducing kitchens into new and renovated schools; improving the nutritional quality of the meals served; and specifically targeting disadvantaged communities including indigenous groups, migrants and ethnic minorities ${ }^{(51)}$. The school food programme now reaches approximately 678000 students $^{(54)}$.

Importantly, since these efforts are situated within a wider anti-hunger and anti-poverty campaign, they are complemented by a suite of other initiatives such as nutritional supplementation, 'community canteens', cooperative food shops, food banks and activities to strengthen local food chains and urban agriculture ${ }^{(51)}$. A critical point about all of these initiatives, including the school meals component, is their shared emphasis on aspects of community building, inclusivity and

\footnotetext{
* The Gini coefficient is a common measure of income inequality. Indices above 0.50 are considered 'high' and those above 0.60, 'very high'. Although income inequality is not the only relevant measure of inequity, as some authors have pointed out, we accept the Gini coefficient as a signal of problematic distribution of resources, benefits and rights.
} 
co-responsibility; for example, the community canteens are envisioned as centres for social and community development where participants can access learning and training, discover experiences of association and acquire a participatory identity in the community ${ }^{(55)}$.

The outcomes of the programme have been positive but incomplete; the previous administration attributed a rapid $10 \%$ decrease in poverty largely to the Bogotá sin hambre programme ${ }^{(56)}$, " and the city positions itself as a leader in food security policy: at present, in Bogotá, $28 \%$ of households are food insecure (against a much higher national average of $42 \%)^{(57)}$. As its programmes evolve, however, Bogotá is beginning to face questions surrounding the breadth of reach and effectiveness of the school canteens, the degree of citizen participation in governance and oversight, and the provenance of food used in the city. While social movements have successfully elevated to the agenda the critical issue of urban market access for small rural producers, for example, those efforts have largely failed to breach the barriers to public food procurement ${ }^{(58)}$. However, as we discuss in the Conclusions, the city's policy approach to food is establishing a promising platform for addressing the new food insecurity - one that deserves the attention of other municipalities and of academics alike.

\section{Conclusions: towards a new agenda for research and action around urban school food}

The new global food scenario and the public health crisis it entails are creating an imperative for policy makers and researchers to address food security on new grounds and under a new rubric. To use the words of Lang, 'the old food policy paradigm is running out of legitimacy ... today's food world is more complex and "messier" and requires a paradigm shift ${ }^{\text {(28) }}$. As an increasing number of scholars are arguing, successfully negotiating this complexity will require turning to new models of public health nutrition and food policy that privilege ecologically complex analyses and more systemic, structural and environmental interventions.

In the current paper we have attempted to show that school food ought to have a privileged place at the food systems reform table. The evidence available from both developed and developing countries points to its potential to address both modes of the food security crisis (under- and mal-nutrition); to integrate structural and environmental with behavioural approaches; and to comprise far-reaching, system-wide efforts that determine the wider structuring and functioning of the food system.

\footnotetext{
* Indeed, the way that Alfredo Sarmiento, Director of the National Human Development Program, described the reduction bears great relevance here. In the case of Bogotá, he said, it was clear that the political decision to work in favor of social rights and equality', in particular the Bogotá sin hambre programme, had played a key role in achieving the rapid decrease in poverty ${ }^{(56)}$.
}

This potential, we believe, is more likely to express itself in cities, where both human populations and environmental degradation are increasingly concentrated and where, precisely for this reason, the new food security crisis manifests in all its bimodality - that is, as a systemic crisis of food quality and quantity, availability and access, production and consumption. For urban governments, this is clearly raising a more and more urgent need for replacing conventional (and largely ineffective) supply-led food security policies with a more systemic approach that promotes a coordination, rather than collection, of reforms. In the context of an emerging and broadly visioned food policy, school food systems stand as a potent intervention site that can both integrate different types of (food security-promoting) reforms and can themselves be integrated into wider (food securitypromoting) policy suites. $\dagger$

As we have argued, the example of Bogotá is particularly relevant here for its innovative rights-based approach to food security and health-promoting school meals. In general, the notion of a right to food - and indeed of a right to health - bears greatly upon how a state understands its responsibility to assume measures addressing food insecurity ${ }^{(60-68)}$. In general, such an approach empowers citizens and promotes their participation in the reform process; it charges not only the state but also other power holders with a (justiciable) responsibility for food security; and it establishes school meals as a well-being service - rather than a commercial one - with assertiveness and finality. At the same time, the notion that rights are indivisible and of equal importance creates a conceptually valuable liaison between food and health: if citizens have not only a right to food but also a right to health, surely they have also a right to the quantity and quality of food that enables health - and perhaps also a right to remediation in the case that the quantity and quality of accessible food instead enable only the contrary, as might be argued in the case of the 'food deserts' dotting many urban areas in rich countries.

We have also seen how innovative school food programmes have been used to generate a wide variety of benefits. In the context of the 'new food equation' and its highly urban manifestation, it is only sensible to query the particular possibilities for urban school food systems to take on new roles in promoting food security. Where nationally enabling contexts for food security do not exist, cities stand out as potentially powerful innovators and implementers. Bogotá is one city that is striving to take the lead on this front with its Bogotá sin hambre

$\uparrow$ Not only do social problems tend to concentrate in cities, so too do the resources to combat them. Capital of all types (economic, social, cultural, intellectual, etc.) also tends to concentrate in cities, and cities consequently often act as fertile ground for social movements. For a lengthier discussion regarding the role of social movements and civil society around urban school food - effectively an exploration of the non-state actors who collectively give thrust and sustenance to the state efforts we discuss herein - see Ashe and Sonnino ${ }^{(59)}$. 
programme, and it has wisely embraced school food as a key platform for intervention. By embedding a renewed ethic into its school food system, Bogotá is doing much more than providing the inputs required for the satisfaction of children's immediate nutritional needs. It is also attempting to build - structurally and culturally - a food system with improved promise for long-term food security and good public health.

The wider potential for urban school food, however, remains as yet too little explored (and perhaps exploited) in practice and too little understood in theory, and this is unfortunate on both counts. Considering the size of the urban school food market and its emphasis on one of the most vulnerable segments of the human population (children), reformative initiatives in this arena arguably have a major role to play in fashioning an urban environment that fosters affirmative multifunctional outcomes of food systems in relation to food security, public health, community development and environmental integrity. Much more work needs to be done to understand the nature, dynamics and transformative potential of these initiatives and to identify the opportunities for pioneering cities to co-produce and exchange knowledge that can ultimately serve as a tool and a roadmap for food security. Indeed, as we have argued in the current paper, the severity of the new food security problem is immense, and so, too, must be the intellectual and practical resources dedicated to its address. In allocating those resources, practitioners and researchers - and the public health nutrition community in particular - should give urban school food a key place on the agenda as both an intervention site and a laboratory for food security policy.

\section{Acknowledgements}

Source of funding: The authors are funded by the Marie Curie Initial Training Network PUREFOOD and members of the Cardiff University School of Planning and Geography. Conflicts of interest: There are no conflicts of interest. Ethics: No ethical approval was sought. Authors' contributions: L.M.A. wrote the original article, performed formatting and conducting the referencing/citations of the article. R.S. participated in the revision process, helping to strengthen the argument by offering a first restructuring of the paper and adding several concrete examples of the article's main themes. Both authors collaborated in finalizing the article's key messages and editing the article. Acknowledgements: The authors gratefully acknowledge the two anonymous reviewers whose constructive suggestions have considerably strengthened the quality of this article.

\section{References}

1. Von Braun J (2007) The World Food Situation. New Driving Forces and Required Actions. Washington, DC: International Food Policy Research Institute; available at http://www. ifpri.org/sites/default/files/pubs/pubs/fpr/pr18.pdf
2. O'Kane G (2012) What is the real cost of our food? Implications for the environment, society and public health nutrition. Public Health Nutr 15, 268-276.

3. Morgan K \& Sonnino R (2010) The urban foodscape: world cities and the new food equation. Cambridge J Regions Econ Soc 3, 209-224.

4. Barling D, Sharpe R \& Lang T (2008) Rethinking Britain's Food Security. London: Centre for Food Policy, City University London.

5. Lang T (2010) Crisis? What crisis? The normality of the current food crisis. J Agrarian Change 10, 87-97.

6. Ingram J, Ericksen P \& Liverman D (2010) Food Security and Global Environmental Change. London: Earthscan.

7. Popkin BM \& Gordon-Larsen P (2004) The nutrition transition: worldwide obesity dynamics and their determinants. Int J Obes Relat Metab Disord 28, Suppl. 3, S2-S9.

8. Dixon J, Omwega A, Friel S et al. (2007) The health equity dimensions of urban food systems. J Urban Health $\mathbf{8 4}$, 118-129.

9. Caraher M \& Coveney J (2004) Public health nutrition and food policy. Public Health Nutr 7, 591-598.

10. Popkin BM (1999) Urbanization, lifestyle changes and the nutrition transition. World Dev 27, 1905-1916.

11. Popkin BM (2001) The nutrition transition and obesity in the developing world. J Nutr 131, issue 3, 871S-873S.

12. Drewnowski A \& Popkin BM (1997) The nutrition transition: new trends in the global diet. Nutr Rev 55, 31-43.

13. Yngve A, Margetts B, Hughes $\mathrm{R}$ et al. (2009) Food insecurity - not just about rural communities in Africa and Asia. Public Health Nutr 12, 1971-1972.

14. Forster T (2011) Food, Agriculture and Cities. Challenges of Food and Nutrition Security, Agriculture and Ecosystem Management in an Urbanizing World. Rome: FAO; available at http://www.fao.org/index.php?id=28645

15. Morgan K (2009) Feeding the city: the challenge of urban food planning. Int Plann Stud 14, 341-348.

16. Sonnino R (2009) Feeding the city: towards a new research and planning agenda. Int Plann Stud 14, 425-435.

17. Maxwell S (1998) Saucy with the gods: nutrition and food security speak to poverty. Food Policy 23, 215-230.

18. Food and Agriculture Organization of the United Nations (1996) Rome Declaration on World Food Security and World Food Summit Plan of Action. World Food Summit, Rome, Italy, 13-17 November 1996. Rome: FAO; available at http://www.fao.org/docrep/003/w3613e/w3613e00.htm

19. Ericksen P (2008) Conceptualizing food systems for global environmental change research. Glob Environ Change 18, 234-245.

20. Counterpart International (2012) Food security and nutrition. http://www.counterpart.org/our-work/areas-of-focus/foodsecurity-and-nutrition (accessed May 2012).

21. ETH Zurich (2012) The Swiss Federal Institute of Technology World food system center. Strategic focus areas. http:// www.worldfoodsystem.ethz.ch/about_us/strategy (accessed May 2012).

22. Kgathi DL, Mfundisi KB, Mmopelwa G et al. (2012) Potential impacts of biofuel development on food security in Botswana: a contribution to energy policy. Energy Policy 43, 70-79.

23. Committee on World Food Security (2000) Who are the Food Insecure? Twenty-sixth Session, Rome, 18-21 September 2000. Rome: FAO; available at http://www.fao.org/docrep/ meeting/x8018e.htm\#P88_1097

24. US Agency for International Development (2010) Feed the future. http://www.usaid.gov/feedthefuture/FTF_Guide.pdf (accessed February 2012).

25. SEEP Network, Catholic Relief Services \& US Agency for International Development (2012) Practitioner learning program rural agricultural finance and food security (RAFFS). http://ruralagriculturefoodsecurity.wordpress.com/resultsand-conclusions/conclusions/ (accessed May 2012). 
26. De Marco M, Thorburn S \& Kue J (2009) 'In a country as affluent as America, people should be eating': experiences with and perceptions of food insecurity among rural and urban Oregonians. Qual Health Res 19, 1010-1024.

27. Rayner G (2009) Conventional and ecological public health. Public Health 123, 587-591.

28. Lang T (2005) Food control or food democracy? Re-engaging nutrition with society and the environment. Public Health Nutr 8, 730-737.

29. Lang T, Barling D \& Caraher M (2009) Food Policy. Integrating Health, Environment \& Society. Oxford: Oxford University Press.

30. Bundy D, Burbano C, Grosh M et al. (2009) Rethinking School Feeding: Social Safety Nets, Child Development, and the Education Sector. Washington, DC: World Bank.

31. Bennett J (2003) Review of School Feeding Projects. London: UK Department for International Development.

32. Espejo F, Burbano C \& Galliano E (2009) Home-Grown School Feeding: A Framework to Link School Feeding with Local Agricultural Production. Rome: World Food Programme.

33. Sumberg J (2011) Linking agricultural development to school feeding in sub-Saharan Africa: theoretical perspectives. Food Policy 36, 341-349.

34. Sumberg J \& Sabates-Wheeler R (2010) Linking Agricultural Development to School Feeding. Working Paper 012. Brighton: Future Agricultures Consortium.

35. Doak C (2002) Large-scale interventions and programmes addressing nutrition-related chronic diseases and obesity: examples from 14 countries. Public Health Nutr 5, 275-277.

36. Scotland of Food and Drink (2011) Healthy School Meals Help Trim the Fat in East Ayrshire. http://www. scotlandfoodanddrink.org/news/article-info/1493/healthyschool-meals-help-trim-the-fat-in-east-ayrshire.aspx (accessed August 2011).

37. Sanchez-Vaznaugh EV, Sánchez BN, Baek J et al. (2010) 'Competitive' food and beverage policies: are they influencing childhood overweight trends? Health Aff (Millwood) 29, 436-446.

38. Atkins Center for Weight and Health, University of California Berkeley (2010) Evaluation of the School Lunch Initiative: Changing Students' Knowledge, Attitudes, and Behavior in Relation to Food. Berkeley, CA: University of California Berkeley.

39. Haroun D, Harper C, Wood L et al. (2011) The impact of the food-based and nutrient-based standards on lunchtime food and drink provision and consumption in primary schools in England. Public Health Nutr 14, 209-218.

40. Sonnino R (2010) Escaping the local trap: insights on re-localization from school food reform. J Environ Policy Plann 12, 23-40.

41. Footprint Consulting (2008) The social return on investment of food for life school meals in East Ayrshire. http:// s3.amazonaws.com/files.posterous.com/temp-2011-07-20/ vlorrxpFEaajtpHbxeqIhGmfutCrgcgqsncpIAyyjgCdJoEDbtBh CszeBcra/FCL_EAC_FFL_SROI_Technical_Report_12Dec08. pdf?AWSAccessKeyId=AKIAJFZAE65UYRT34AOQ\&Expires $=$ $1343385904 \&$ Signature $=$ Nc83S8t5JBgp7W3i9nZ7KUdUjCE\%3D (accessed July 2012).

42. Morgan K \& Sonnino R (2008) The School Food Revolution: Public Food and the Challenge of Sustainable Development. London: Earthscan.

43. Morgan K (2008) Greening the realm: sustainable food chains and the public plate. Regional Stud 42, 1237-1250.

44. Poppendieck J (2010) Free for All: Fixing School Food in America. Berkeley, CA: University of California Press.

45. Schafft KA, Jensen EB \& Hinrichs CC (2009) Food deserts and overweight schoolchildren: evidence from Pennsylvania. Rural Sociol 74, 153-177.

46. Kwan A, Mancinelli K \& Freudenberg N (2010) Recipes for Health: Improving School Food in New York City.
New York: Hunter College Healthy Public Policies Projects and City Harvest.

47. Otsuki K (2011) Sustainable partnerships for a green economy: a case study of public procurement for homegrown school feeding. Nat Resour Forum 35, 213-222.

48. Sonnino R (2009) Quality food, public procurement and sustainable development: the school meal revolution in Rome. Environ Plann A 41, 425-440.

49. Rocha C \& Lessa I (2009) Urban governance for food security: the alternative food system in Belo Horizonte, Brazil. Int Plann Stud 14, 389-400.

50. UN-Habitat (2008) State of the World's Cities: 2008/2009: Harmonious Cities. London: Earthscan.

51. Garzón L (2003) Bogotá sin hambre. Por un compromiso social contra la pobreza en Bogotá. Bogotá: Alcaldìa Mayor de Bogotá

52. Instituto Colombiano de Bienestar Familiar (2007) Lineamentos técnico-administrativos y estándares para la asistencia alimentaria al escolar. Programa de alimentación escolar. Bogotá: ICBF.

53. Ministerio de Educación Nacional (2007) La seguridad alimentaria. Medellín: Congreso Internacional de Seguridad Alimentaria.

54. Mercados Campesinos (2010) Con actividades gastronómicas, Bogotá participa en la semana de la alimentación. http://prensamercadoscampesinos.blogspot.com/2010/ 10/con-actividades-gastronomicas-bogota.html (accessed October 2011).

55. Alimentación Sustentable en América Latina (2011) Entrevista a julio figueroa. Programa Bogotá bien alimentada. http:// alimescolar.sistematizacion.org/entretiens/liste-des-entretiens/ ?tx_panel_pi1[afficher]=det_entretien\&tx_panel_pi1[uid] =50 (accessed March 2012).

56. Redacción Bogotá (2007) Pobreza en Bogotá se redujo del $46,3 \%$ al 28,5\% en cinco años. El Tiempo.com, 15 March 2007; available at http://www.eltiempo.com/archivo/ documento/CMS-3478059

57. Fonseca Centeno Z, Heredia Vargas A, Ocampo Tellèz P et al. (2010) Encuesta Nacional de la Situación Nutricional en Colombia 2010 - ENSIN. Bogotá: ICBF.

58. Pesquera A (2011) Leading by example: How cities came to link rural producers with urban food markets in Colombia. Oxfam Programme Insights, April 2011 issue; available at http://policy-practice.oxfam.org.uk/publications/leadingby-example-how-cities-came-to-link-rural-producers-withurban-food-mark-133410

59. Ashe L \& Sonnino R (2012) Finding convergence in diversity: New York City school food and the future of the food movement. Special issue on Feeding the City. Int Plann Stud (In the Press).

60. Anderson M (2008) Rights-based food systems and the goals of food system reform. Agric Hum Values 25, 593-608.

61. Marks S (2000) The Human Rights Framework for Development: Five Approaches. Cambridge, MA: Harvard University.

62. Wheeler J \& Pettit J (2005) Developing rights? Relating discourse to context and practice. IDS Bull 36, issue 1, $1-8$.

63. VeneKlasen L, Miller V, Clark C et al. (2004) Rights-based Approaches and Beyond: Challenges of Linking Rights and Participation. IDS Working Paper no. 235. Brighton: Institute of Development Studies; available at http:// www.ids.ac.uk/files/Wp235.pdf

64. Institute of Development Studies (2003) The rise of rights. Rights-based approaches to international development. IDS Policy Briefing issue 17, May 2003; available at http:// www.ids.ac.uk/files/Pb17.pdf

65. Piron L-H (2002) The Right to Development. A Review of the Current State of the Debate for the Department for 
International Development. London: UK Department for International Development, Social Development Department. 66. De Schutter O (UN Special Rapporteur on the Right to Food) (2010) Countries tackling hunger with a right to food approach. Briefing Note 01 - May 2010; available at http:// www2.ohchr.org/english/issues/food/docs/Briefing_Note_ 01_May_2010_EN.pdf
67. Rideout K, Riches G, Ostry A et al. (2007) Bringing home the right to food in Canada: challenges and possibilities for achieving food security. Public Health Nutr 10, 566-573.

68. Haddad L \& Oshaug A (1998) How does the human rights perspective help to shape the food and nutrition policy research agenda? Food Policy 23, 329-345. 